\title{
Management Practices to Reduce Lupine-Induced Crooked Calf Syndrome in the Northwest
}

\author{
By Kip E. Panter, Clive C. Gay, Roy Clinesmith, and Tom E. Platt
}

\section{On the Ground}

- Lupines are legumes and may provide a source of protein and other nutrients late in the growing season. However, toxins are concentrated in the pods and will poison animals, especially sheep, if gluttonous consumption occurs.

- Risk of lupine-induced crooked calf syndrome depends on multiple factors including lupine population density, availability of other quality forages, weather/climate patterns, breeding schedules, stage of pregnancy, grazing management strategies, and others.

- Using stockers, open heifers, or other livestock species to graze lupine-infested pastures is one way to utilize high-risk rangelands. Do not overgraze as animals may be poisoned if forced to subsist on lupines.

- Identify lupines and obtain a chemical analysis for risk assessment on rangelands before turning pregnant cows out. Plant samples may be submitted to the USDA-Agricultural Research Service Poisonous Plant Research Laboratory for identification, chemical analysis, and a follow-up risk assessment at no charge. Contact kip.panter@ars.usda.gov.

Keywords: crooked calf syndrome, lupine, cleft palate, poisonous plants, quinolizidine alkaloid, pipendine alkaloid, anagyrine, ammodendrine.

Rangelands 35(2):12-16

doi: 10.2111/RANGELANDS-D-12-00074.1

(C) 2013 The Society for Range Management

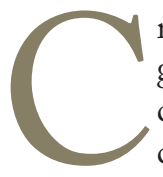

rooked calf syndrome (CCS) is a descriptive term given to a pattern of skeletal malformations and cleft palate that occur in the offspring of range cows that graze certain lupine species during early pregnancy (Fig. 1). ${ }^{1,2}$ The anomalies are characterized by the presence of limb twisting or bowing (usually the forelimbs with occasional hind-limb involvement), spinal column deviations affecting the neck and back, and other secondary skeletal defects such as rib cage deformities. Occasional cleft palate in calves is also associated with the syndrome. Cleft palate may occur with or without the skeletal malformations depending on the stage of pregnancy when the cow ingests lupine. Because the susceptible period of gestation in pregnant cows for cleft palate induction (40-50 days gestation) is very narrow, its appearance can potentially be used to retrospectively determine a timeline when cattle began to eat lupines.

Lupines are beautiful legume species that flourish in the northwestern United States (Figs. 2 and 3). There are over 500 identified species, with 150 found in the intermountain western United States and western Canada. ${ }^{3}$ Range lupines are perennial or annual forbs found in a variety of habitats at all elevations from lowland deserts to the alpine crests. Lupine species are difficult to classify due to similar morphological (shape and size) characteristics and lack of diagnostic features. Broad geographical distribution, frequent hybridization, and habitat diversity contribute to the difficulty in accurate classification. Taxonomists, some of whom are "splitters" and others "lumpers," do not agree on many aspects of lupine classifications. Therefore, taxonomic identification of lupines suspected to cause CCS is of little use without chemical characterization. For example, seven chemotypes of Lupinus sulphureus (sulphur lupine) were investigated throughout its northwestern geographical distribution and four of those contained the teratogenic (malformation-causing) alkaloid anagyrine. ${ }^{4}$ The chemotype found near Pendleton, Oregon, poses a high risk of causing CCS and was responsible for a $56 \%$ incidence in a single cow herd in the 1990s (Fig. 3). ${ }^{5} \mathrm{~A}$ second example is a population of Lupinus leucophyllus (velvet lupine), also found near Pendleton, Oregon, which contains no teratogenic alkaloids and poses no risk of CCS, yet the same taxonomic species growing on the Channeled Scablands of east-central Washington contains substantial amounts of 


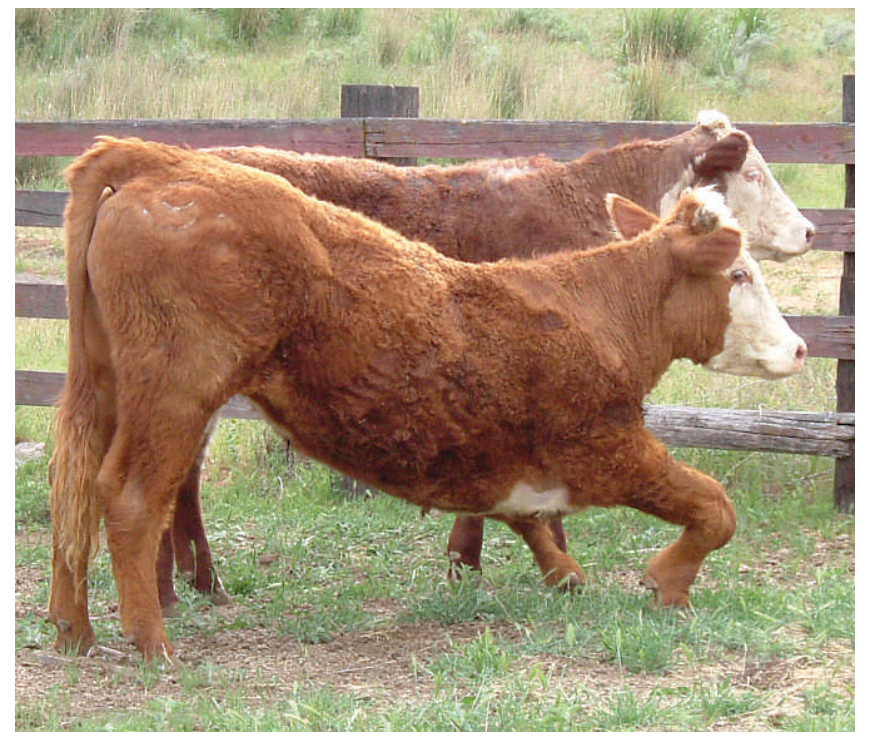

Figure 1. Yearling crooked calf salvaged for home use. As the steer continues to grow, the front legs will continue to bow and break down.

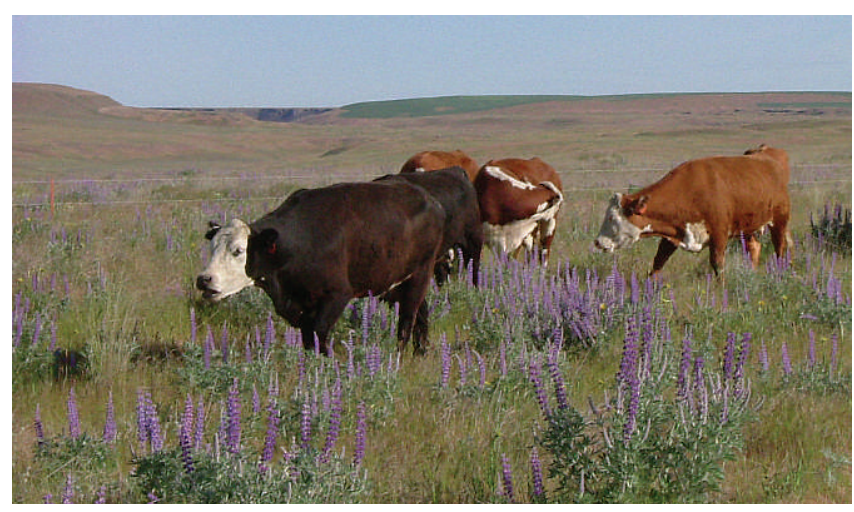

Figure 2. Velvet lupine (Lupinus leucophyllus) grazed by cattle in a pasture of the Channeled Scablands region of east-central Washington where crooked calf syndrome is endemic.

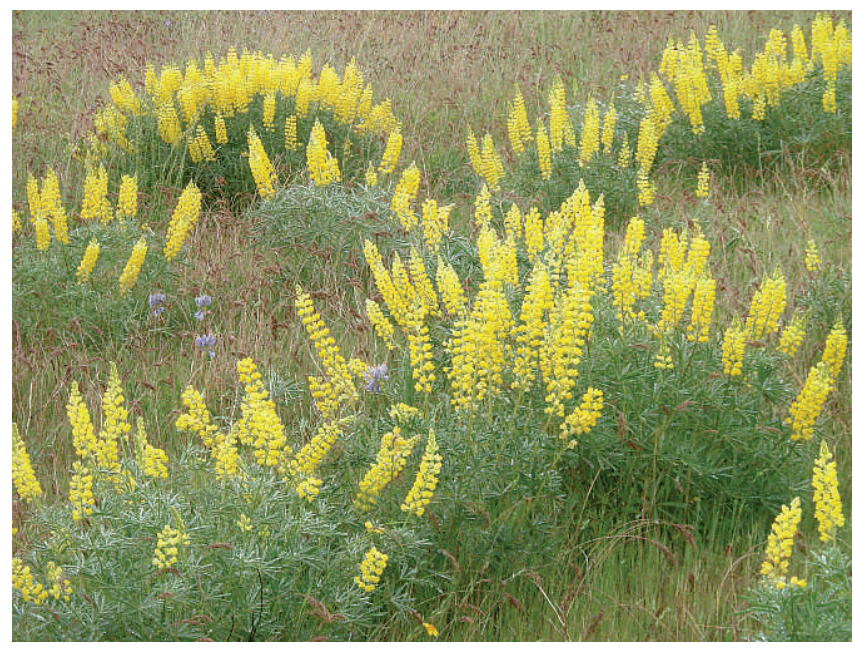

Figure 3. Sulphur lupine (Lupinus sulphureus) near Pendleton, Oregon, responsible for an outbreak of crooked calf syndrome in $1992 .^{5}$ the teratogenic alkaloid anagyrine and is responsible for multiple outbreaks of CCS on multiple ranches including catastrophic losses in 1997 (Fig. 4). In addition to which lupine exists on any given ranch, lupine population cycles, availability of other quality forages, and grazing management practices all contribute to the incidence of CCS.

While lupines are responsible for large losses to cattle producers in the Northwest, lupines do have forage value and wild legumes are good soil stabilizers and enhance nitrogen in the soils for the other grasses and forbs. In the Channeled Scablands, lupines become an important forage source about early to mid-July when the annual grasses and forbs become mature and dry, and are of low grazing quality. ${ }^{6}$ Table 1 summarizes the relative feed value of the forages typical for the scablands in early to mid-July. One can easily see why cattle graze velvet lupine during this period of time; if this coincides with the susceptible stage of pregnancy in cows and lupine plants are relatively abundant, the outcome is an increase in CCS.

\section{Chemistry}

Alkaloids found in the lupine family are of two classes, quinolizidine and piperidine, both of which contain toxic and teratogenic compounds. Both anagyrine (the quinolizidine alkaloid) and ammodendrine (the piperidine alkaloid) will cause CCS and both are considered diagnostic when evaluating lupine species for CCS risk. Most lupines that have been associated with CCS contain the quinolizidine alkaloid anagyrine. If both alkaloids are present, which happens occasionally, the risk of CCS is very high. If plants containing one or both of these alkaloids are grazed during the sensitive period of gestation, large losses can be expected. During the 1970s, Dr Richard Keeler (deceased) did extensive research in the Northwest on lupine species that caused large outbreaks of CCS. Through this research he identified anagyrine as the principle teratogenic alkaloid. ${ }^{7}$ Since that time, research has shown that anagyrine is the only quinolizidine alkaloid with activity in cows and that ammodendrine occurs in relatively few lupine species.

Alkaloid concentration and chemical profiles vary widely between and within lupine species and populations. Season, year, environment, weather patterns, geographical location, and plant phenology may all influence alkaloid concentrations in plants. Recent research suggests that the alkaloid profile is relatively consistent over time and can be used as an identifying taxonomic feature ${ }^{8}$ to differentiate lupine species and evaluate potential risk. Early-growth lupine is high in alkaloid content and potentially high risk for CCS. As the plant matures the alkaloid pool remains relatively consistent but the alkaloids are translocated to the flowers and seed pods. After seed pods shatter, the risk of lupine poisoning and CCS is virtually eliminated. This information is important in determining risk factors for CCS as the season progresses.

\section{What is the Mechanism for CCS?}

Research at the Poisonous Plant Research Laboratory (PPRL) over the last 20 years determined that the skeletal 
Table 1. Nutritional quality of lupine compared to other range plants on the Channeled Scablands of eastern Washington (July 2007)

\begin{tabular}{|l|c|c|c|}
\hline & $\%$ CP & $\%$ NDF & $\%$ IVTD \\
\hline Lupine & $8-15$ & $58-62$ & $59-62$ \\
\hline Lupine pods & $30-45$ & ND & ND \\
\hline Grasses & $4.5-5.5$ & $66-72$ & $57-64$ \\
\hline Forbs & $5.5-6.5$ & $61-63$ & $51-56$ \\
\hline
\end{tabular}

CP indicates crude protein; NDF, neutral detergent fiber, an indicator of non digestible fiber (a higher number indicates a lower-quality feed); IVTD, in vitro total digestibility, an indicator of total digestibility (a higher number represents a better-quality feed); and ND, not determined.

malformations and cleft palate characteristic of CSS are the result of alkaloid-induced reduction in fetal movement. ${ }^{9}$ The severity of the malformation is dependent on how much lupine is ingested, the alkaloid content of the lupine, how many continuous days it is ingested, and at what stage of pregnancy the cow ingested the lupine. CCS will not occur with a single exposure of lupine or even a few days of lupine ingestion. For cleft palate to occur, the pregnant cow must graze lupine consistently for 5 to 10 days during the gestation period of $40-50$ days. ${ }^{10}$ For skeletal malformations to occur, the pregnant cow must graze lupine consistently for 10 days or longer during the gestation period that includes days 50-100. Research has demonstrated that peak alkaloid levels occur in the cow within 30 minutes to 1 hour after lupine ingestion and that fetal movement is depressed in a reverse relationship to serum alkaloid levels (Fig. 5). The alkaloid rapidly clears from the dam's circulation within 12-24 hours allowing fetal movement to return to normal. As the fetus gets further advanced, more lupine is required to be ingested by the dam to keep the fetus in an immobile state. This information is important when considering potential intervention and grazing management to reduce the overall impact of lupine. Recent research at the PPRL demonstrated this by feeding lupine to pregnant cows intermittently over the susceptible period of pregnancy. Cows were fed lupine for 10 days followed by no lupine for 5 days. Circulating alkaloid (anagyrine) levels were compared with fetal movement in relationship to lupine ingestion (Fig. 5). If ranch managers have the option, once range riders observe individual cows eating lupine, those cows may be pulled and moved to alternative pastures or the entire herd may be moved to a clean pasture, breaking the cycle of lupine ingestion. Intermittent grazing may allow optimum utilization of the lupine-infested rangelands but minimize risk of CCS.

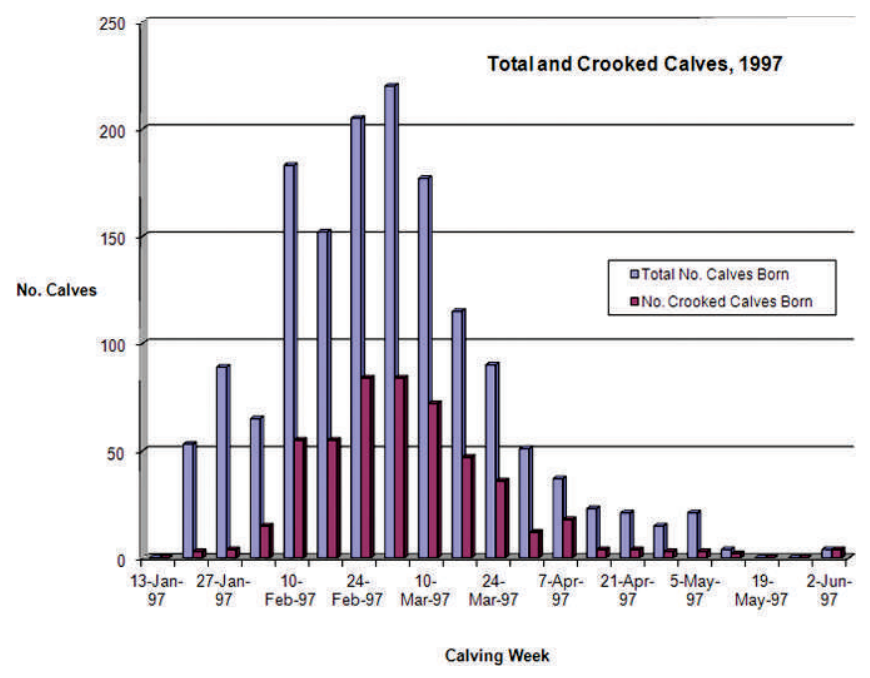

Figure 4. Incidence of crooked calf syndrome on 12 ranches involved in a catastrophic occurrence of this problem on the Channeled Scablands in 1997 (reprinted with permission). ${ }^{10}$ The light bars indicate total number of calves born on a given date and the dark bars indicate the number of crooked calves born on that date.

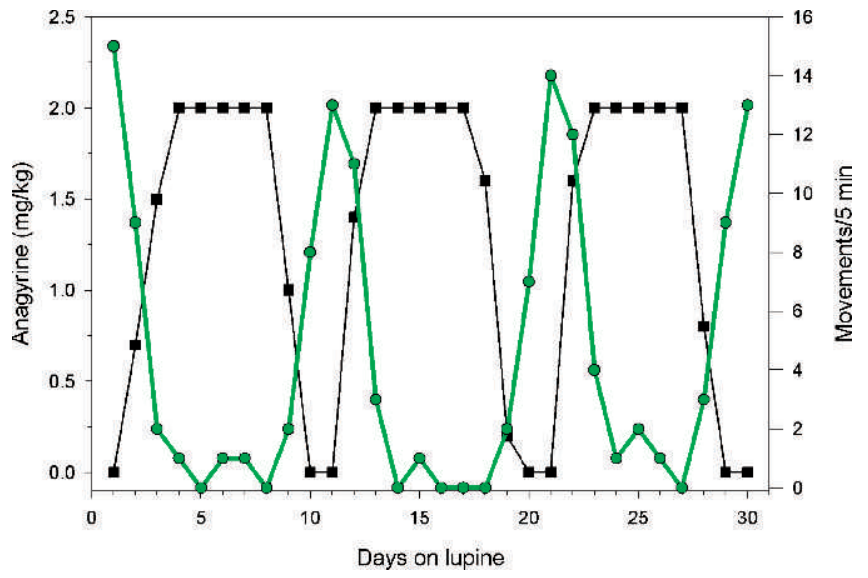

Figure 5. Preliminary data demonstrating the effects of intermittent dosing of lupine on fetal movement. Note the blood levels of the alkaloid anagyrine (black squares) in relationship to fetal movement (green circles). As blood anagyrine levels increase, fetal activity decreases and vice versa.

\section{Risk Factors}

In regions where lupine-induced CCS is endemic, late spring or early summer breeding schedules create the highest potential risk for CCS. Shifting breeding schedules a week or two earlier or later may temporarily reduce risk, but unless a major shift occurs, i.e., a change to a fall calving schedule, this temporary benefit may only work for a season or two. The reason for this temporary benefit is because other factors contribute to CCS, such as environmental or weather patterns, lupine population cycles, or quality and amount of alternate forage. At the same time, there is individual cow-to-cow variability in propensity to graze lupine and in genetic sensitivity to the alkaloids. Ultimately, preventing cattle from grazing highrisk lupines for extended periods of time, and during the sensitive stages of pregnancy, is the only way to eliminate CCS. 
In grazing studies done on the Channeled Scablands over the last 10 years, it has become evident that there are "lupine eaters" in any given herd. Although evidence is not conclusive, those cows that have a deformed calf should be eliminated from the herd and their heifers should not be kept for replacements. Having said this, there is a limitation to how successful this management approach is; it will depend on individual ranch needs and approaches. Some ranchers that experienced large losses in a given season from CCS shifted to a fall calving schedule and essentially eliminated the risk. However, timing of fetal exposure to lupine alkaloids is always the determining factor for risk.

\section{Ranchers' Perspective}

Based on our experience working with ranchers, the following range strategies to manage CCS have been used. Most commonly, they avoid using pastures with known crooked calf history as breeding pastures, or they move cattle to lupine-free pastures midsummer when lupine grazing begins. A few ranchers with smaller holdings use herbicides to control lupine, but herbicide application must be repeated every 5 to 8 years and is not cost effective on large pastures. A few ranchers have altered the breeding season or switched from spring to fall calving. Others, acting on the theory that cattle are attracted to lupine for its protein content, supplement protein when grasses senesce in midsummer. This protein hypothesis is being investigated at the PPRL. Recent research results (Panter, unpublished data, 2011) demonstrated that fetal paralysis from lupine is short-lived when lupine ingestion stops (Fig. 5). This supports some ranchers who rotate pastures weekly in order to break cows' lupine feeding cycle. To various degrees, all of these strategies will help manage CCS and can be adapted to individual ranches.

\section{Management Recommendations}

Reducing losses from lupine-induced CCS requires multiple approaches to be successful. However, a simple rule may be applied: avoid grazing toxic lupines by pregnant cows during the susceptible stages of gestation (days 40-100) on pastures where lupines containing anagyrine and/or ammodendrine are present. Having said this, these ranges can be utilized optimally by following a few management practices:

1) Identify potential poisonous plants (in this case, lupines) and determine which specific lupines are present.

2) Determine the chemical profile of the lupine species. Risk assessment is based on alkaloid profiles and concentration of anagyrine or ammodendrine. Lupine plants may be submitted to the PPRL for taxonomic identification and chemical analysis at no charge. If anagyrine and/or ammodendrine are present, evaluate the concentration in relation to other alkaloids. Year-to-year variation in alkaloid concentration may occur, affecting the incidence of CCS, but the overall alkaloid profile remains the same. Monitoring of this variation at global positioning system- identified sites on the scablands over the past several years suggests that a year in which there is a high concentration of anagyrine relative to other alkaloids is followed by a year of higher incidence of CCS. ${ }^{11}$ If ongoing research continues to support this finding, measuring alkaloid concentrations early in the growing season (May) would allow an early prediction of a year of higher incidence and enable ranchers to strategize alternates to lupine grazing during the summer months.

3) Evaluate historical incidence of CCS on the range, lupine population cycles, range condition, and forage quality and availability. Avoid overstocking as this may force cows to start grazing lupines earlier than expected.

4) Adjust breeding schedules to avoid exposing pregnant cows to lupines when they are at highest risk (40-100 days gestation). Where high incidence of CCS occurred in multiple years, fall calving schedules have virtually eliminated CCS.

5) Restrict access to lupine in late summer when cattle normally begin eating lupine and when anagyrine levels are elevated in seed pods.

6) Use intermittent grazing, moving cows to clean pastures when lupine grazing is observed or pull "lupine eaters" as they start to graze lupine plants (Fig. 5). This requires intense management and may not be practical for some ranchers. Once seed pods have shattered, cattle can be safely returned to lupine pastures.

7) Utilize high-risk lupine pastures by using stockers, open heifers, or other livestock species to harvest forages. Lupine is nutritious forage, particularly on dormant rangelands dominated by annual grasses. Some ranchers have implemented this management strategy and successfully utilized their lupine-infested range and avoided crooked calves.

8) Use herbicide control. Although generally not economical on large pastures, smaller ranches with few options may consider controlling lupines with herbicides. Lupine seed reserves are high in soil profiles and will germinate when conditions are right, therefore repeat treatment is required every 5-8 years. Herbicides may be used to clean up a pasture for use in the intermittent approach to managing lupine.

\section{Conclusions}

There are many factors that impact the overall incidence of lupine-induced crooked CCS, including large occasional outbreaks. On many ranches in the Northwest a 1-5\% incidence of CCS is accepted as the "cost of doing business." However, even this level of CCS is economically important and affects the economic sustainability of many producers and certainly cuts into the profit margin of affected ranchers. Frequently (every 5-10 years), the incidence exceeds this level and can be catastrophic to many ranches. Lupine population cycles and availability of other quality forages are important factors in CCS incidence. Improving rangeland conditions through restoration efforts using improved grass species or introducing forb species may provide long-term solutions. 
For example, preliminary studies have demonstrated that improved wheat grass cultivars and forage kochia may compete with annual grasses and provide alternative quality forages late in the grazing season. Lupine seeds remain viable in the soil for years or decades and when optimum weather conditions exist, populations will increase accompanied with an increase in CCS. Weather patterns impact lupine populations and significant emergence of seedlings following a wet winter and spring can be a prelude to a major outbreak of CCS the following season. The nutritional status of cows is also a significant consideration. Cows in adequate to good body condition are less likely to graze lupines and other poisonous plants. Although there are other factors involved in CCS, the management suggestions in this paper can be tailored to each region or individual ranch and used to reduce the impact of lupine-induced CCS in the Northwest.

\section{References}

1. Panter, K. E., L. F. James, and D. R. Gardner. 1999. Lupines, poison-hemlock and Nicotiana spp: toxicity and teratogenicity in livestock. Journal of Natural Toxins 8(1):117-134.

2. Lee, S. T., K. E. Panter, C. C. Gay, J. A. Pfister, M. H. Ralphs, D. R. Gardner, B. L. Stegelmeier, E. S. Motteram, D. Cook, K. D. Welch, B. T. Green, and T. Z. Davis. 2008. Lupine-induced crooked calf disease: the last 20 years. Rangelands 30(6):13-18.

3. Cronguist, A., A. H. Holmgren, N. H. Holmgren, J. C. ReveAL, AND P. K. Holmgren. 1989. Intermountain flora: vascular plants of the Intermountain West, USA. In: R. C. Barneby [ED.]. Fabales (vol. 3B). Bronx, NY, USA: New York Botanical Garden. p. 236-268.

4. Cook, D., S. L. Lee, D. R. Gardner, J. A. Pfister, K. D. Welch, B.T. Green, T. Z. Davis, and K. E. Panter. 2009. The alkaloid profiles of Lupinus sulphureus. Journal of Agricultural and Food Chemistry 57:1646-1653.

5. Panter, K. E.D. R. Gardner, C. C. Gay, L. F.James, R. Mills, J. M. GaY, AND T. J. BALdwin. 1997. Observations of Lupinus sulphureus-induced crooked calf disease. Journal of Range Management 50:587-592.
6. Ralphs, M. H., K. E. Panter, C. Gay, E. Motteram, and S. T. LEe. 2006. Cattle consumption of velvet lupine (Lupinus leucophyllus) in the Channel Scablands of eastern Washington. Rangeland Ecology Eं Management 59:204-207.

7. Keeler, R. F. 1976. Lupin alkaloids from teratogenic and nonteratogenic lupins. III. Identification of anagyrine as the probable teratogen by feeding trials. Journal of Toxicology and Environmental Health 1:878-889.

8. Cook, D., S. T. Lee, J. A. Pfister, C. A. Stonecipher, K. D. Welch, B. T. Green, and K. E. Panter. 2012. Alkaloid profiling as an approach to differentiate Lupinus garfieldensis, Lupinus sabinianus, and Lupinus sericeus. Phytochemical Analysis 23:278-284.

9. Panter, K. E., T. D. Bunch, R. F. Keeler, D. V. Sisson, And R. J. Callan. 1990. Multiple congenital contractures (MCC) and cleft palate induced in goats by ingestion of piperidine alkaloid-containing plants: Reduction in fetal movement as the probable cause. Clinical Toxicology 28:69-83.

10. Panter, K. E., D. R. Gardner, and R. J. Molyneux. 1998. Teratogenic and fetotoxic effects of two piperidine alkaloidcontaining lupines (L. formosus and L. arbustus) in cows. Journal of Natural Toxins 7:131-140.

11. Gay, C. C., K. E. Panter, E. S. Motteram, J. M. Gay, H. Hantz, T. Wierenga, and T. Platt. 2007. Risk factors for lupine-induced crooked calf disorder in east-central Washington State. In: K. E. Panter, T. L. Wierenga, and J. A. Pfister [eds.]. Poisonous plants: global research and solutions. Cambridge, MA, USA: CABI. p. 156-164.

Authors are Reproductive Toxicologist and Research Leader, USDA-ARS Poisonous Plant Research Laboratory, $1150 \mathrm{E}$ 1400 N, Logan, UT 84341, USA, kip.panter@ars.usda.gov (Panter); Professor Emeritus, Field Disease Investigation Unit, College of Veterinary Medicine, Washington State University, Pullman, WA 99164, USA (Gay); Cattle Rancher, Ritzville, WA 99169, USA (Clinesmith); Area Extension Educator, Washington State University, Lincoln County, Davenport, WA 99122, USA (Platt). 